\title{
HPV-16 E7 expression up-regulates phospholipase $D$ activity and promotes rapamycin resistance in a pRB-dependent manner
}

\author{
Tatiana Rabachini ${ }^{1 *}$ (D) Enrique Boccardo ${ }^{1,3}$, Rubiana Andrade ${ }^{3}$, Katia Regina Perez ${ }^{2,4}$, Suely Nonogaki ${ }^{5}$,
} lolanda Midea Cuccovia ${ }^{2}$ and Luisa Lina Villa $a^{1,6}$

\begin{abstract}
Background: Human Papillomavirus (HPV) infection is the main risk factor for the development and progression of cervical cancer. HPV-16 E6 and E7 expression is essential for induction and maintenance of the transformed phenotype. These oncoproteins interfere with the function of several intracellular proteins, including those controlling the PI3K AKT/mTOR pathway in which Phospolipase D (PLD) and Phosphatidic acid (PA) play a critical role.

Methods: PLD activity was measured in primary human keratinocytes transduced with retroviruses expressing HPV-16 E6, E7 or E7 mutants. The cytostatic effect of rapamycin, a well-known mTOR inhibitor with potential clinical applications, was evaluated in monolayer and organotypic cultures.

Results: HPV-16 E7 expression in primary human keratinocytes leads to an increase in PLD expression and activity. Moreover, this activation is dependent on the ability of HPV-16 E7 to induce retinoblastoma protein (pRb) degradation. We also show that cells expressing HPV-16 E7 or silenced for pRb acquire resistance to the antiproliferative effect of rapamycin.
\end{abstract}

Conclusion: This is the first indication that HPV oncoproteins can affect PLD activity. Since PA can interfere with the ability of rapamycin to bind mTOR, the use of combined strategies to target mTOR and PLD activity might be considered to treat HPV-related malignancies.

Keywords: HPV, E7, PLD, Phospholipase, Rapamycin, Phosphatidic acid, PA, mTOR, pRb

\section{Background}

Human papillomavirus (HPV) is the most prevalent sexually transmitted infection and a necessary cause of cervical cancer, the third most common cancer in women worldwide [1]. More than $99 \%$ of cervical cancers contain DNA of HPV high-risk types [2]. In addition, HPV DNA is also found in a significant percentage of other anogenital lesions as well as oral and oropharyngeal tumors [3-5]. HPV-16 is the most prevalent type and it is found in almost $50 \%$ of all cervical cancer cases [6]. The two major HPV oncoproteins, E6 and E7, are consistently expressed

\footnotetext{
* Correspondence: tatianarabachini@hotmail.com

'Ludwig Institute for Cancer Research - Hospital Sírio-Libanês, São Paulo, SP. Brazil

Full list of author information is available at the end of the article
}

in all HPV positive cancers. The expression of these proteins in primary human keratinocytes effectively induces their immortalization [7]. Furthermore, when grown under conditions that allow stratification and the formation of skin-like structures, cells immortalized with E6 and E7 from high-risk HPV types display morphological hallmarks of high-grade squamous intra-epithelial lesions, well-established precursors of cervical cancer [8]. The best characterized activity of HPV-16 E6 and E7 is their ability to bind to and induce the proteasome-mediated degradation of tumor suppressors $\mathrm{p} 53$ and $\mathrm{pRb}$, respectively $[9,10]$. Besides, both HPV-16 E6 and E7 are able to bind to and alter the biological function of several other cellular proteins [11]. Among them are many members of the phosphatidylinositol (PI)-3-kinase

(c) The Author(s). 2018 Open Access This article is distributed under the terms of the Creative Commons Attribution 4.0 International License (http://creativecommons.org/licenses/by/4.0/), which permits unrestricted use, distribution, and 
(PI3K)/Akt/mammalian target of rapamycin (mTOR) signaling pathway [12]. The PI3K/Akt/mTOR signaling axis plays a very important role in HPV-induced carcinogenesis by acting through multiple cellular and molecular events [13]. Although the regulation of mTOR through PI3K/AKT has been extensively described, another mechanism contributing to activation of mTOR has been proposed. Phosphatidic acid (PA), a product of phospholipase $\mathrm{D}$, is required for mTORC1 activation by mitogens as well as amino acid signals [14-16]. More recently, PA was identified as a major product capable of displacing DEPTOR, a mTOR binding protein that normally functions to inhibit both mTORC1 and mTORC2 pathways [17]. PA species with unsaturated fatty acids chains, such as those produced by PLD, bind with high affinity to the FRB domain of mTOR in a manner that is competitive with its inhibitor rapamycin. As a consequence, elevated PLD activity has been associated to rapamycin resistance $[18,19]$. In addition, phospholipase D enzymes play a fundamental role in cells: they maintain the integrity of cellular membranes and they participate in cell signaling including cytoskeletal dynamics, cell migration, intracellular protein trafficking, and cell proliferation. Consistent with this data, increased PLD activity has been reported in a large number of human cancers, including breast, colon, gastric, and kidney [20].

Our results show that upon HPV-16 E7 expression, primary human foreskin keratinocytes upregulate PLD protein levels and activity. Such effect is dependent on the integrity of the E7 LxCxE binding motif and, ultimately to the ability of HPV-16 E7 to induce pRb degradation and promote immortalization. We also show that organotypic cultures of keratinocytes expressing HPV-16 E7 become resistant to the antiproliferative effect of rapamycin.

\section{Methods \\ Cell culture}

Low passage-pooled neonatal foreskin keratinocytes or Primary Human Keratinocytes (cat no. 192906) (Lonza Walkersville, Inc., Walkersville, MD) were maintained in K-SFM media supplemented with $5 \mu \mathrm{g} / \mathrm{L}$ EGF and $50 \mathrm{mg} / \mathrm{L}$ bovine pituitary extract (BPE) (Invitrogen, Carlsbad, CA, USA).

\section{Recombinant retroviruses and retroviral-mediated gene transfer}

Retroviral vectors pLXSN-neo, pLXSN-E6, -E7, -E6E7, E7E26G and -E7CVQ68-70AAA were kindly provided by Dr. Denise Galloway (Fred Hutchinson Cancer Center, Seattle, USA). Recombinant retroviruses were produced from the amphotropic packaging cell line GP + envAm12 as described earlier [21]. Early passage PHKs were infected with different retroviruses at the same multiplicity of infection (MOI).

\section{pRb downregulation}

Specific shRNAs clones for $\mathrm{pRB}$ silencing were selected from the MISSION ${ }^{\circ}$ shRNA Human Gene Family SetTumor Suppressors (SH0531, Sigma-Aldrich, St. Louis, MO, USA) and transfected in HEK-293 T cells (ATCC cat. no. 3216) together with MISSION ${ }^{\circ}$ Lentiviral Packaging Mix (Sigma-Aldrich, St. Louis, MO, USA) using FuGENE $^{\bullet}$ HD Transfection Reagent (Promega, Madison, WI, USA) according to the manufacturer's instructions. Supernatants containing lentivirus were collected after 48 and $72 \mathrm{~h}$ after transfection. Lentiviral particles titer was determined using an HIV-1 p24 antigen enzymelinked immunosorbent assay (ELISA) kit (ZeptoMetrix Corporation, Buffalo, NY, USA). Sub-confluent cultures of primary human keratinocytes were infected with lentiviral particles (MOI 5) expressing specific shRNA. After 2 days cells were selected with $2.5 \mu \mathrm{g} / \mathrm{ml}$ of puromycin (Sigma-Aldrich, St. Louis, MO, USA) until complete death of uninfected cells was observed.

\section{Organotypic raft cultures}

Organotypic raft cultures of PHK were prepared as described elsewhere [22]. Raft cultures were allowed to differentiate for 9 days and rapamycin (Calbiochem, San Diego, CA, USA) was added to a final concentration of $100 \mathrm{ng} / \mathrm{ml}$ at day 6. Bromodeoxyuridine (BrdU) (SigmaAldrich, St Louis, MO, USA) was added to a final concentration of $50 \mu \mathrm{g} / \mathrm{ml}$ for the last $12 \mathrm{~h}$. The rafts were then harvested, fixed in formalin and paraffin embedded.

\section{Immunohistochemistry}

Raft sections were deparaffinized and dehydrated in xylene and alcohol sequential baths. The endogenous peroxidase activity was quenched with $3 \% \mathrm{H}_{2} \mathrm{O}_{2}$ after antigen retrieval in boiling citrate buffer. Primary antibodies against BrdU (1:400; Zymed, San Francisco, CA, USA), p53 DO-7 (1:400; DakoCytomation, Glostrup, Denmark) and pRb (1:500; Novocastra, Newcastle-upon-Tyne, UK) were incubated for $18 \mathrm{~h}$ in $1 \%$ bovine serum albumin-phosphate buffered solution. After incubation with secondary antibody, antigens were detected with streptavidin-biotin-peroxidase complex (StreptABComplex/HRP Duet Mouse/Rabbit DakoCytomation, Dako). Chromogenic detection of peroxidase was performed with diaminobenzidine (DAB) substrate (Sigma-Aldrich, St Louis, MO, USA). The percentage of BrdU-positive/total nuclei was determined by direct counting cell nuclei. At least 3000 nuclei were counted per experiment. 


\section{Cell proliferation assays}

For Alamar blue based proliferation analysis cells silenced with lentiviral particles (MOI 5) expressing the shRNA described above and appropriate controls were seeded in octuplicate in 96 wells plates (2000 cells/well). After $72 \mathrm{~h}$ $10 \mu \mathrm{L}$ of Alamar blue (Life Technologies, Carlsbad, CA) were added per well and cells were incubated at $37^{\circ} \mathrm{C}$ for 4 to $7 \mathrm{~h}$. After this period, Alamar Blue reduction was monitored in at 570 e $600 \mathrm{~nm}$ in an Epoch Microplate Spectrophotometer (Bio-Tek, Winooski, VT, USA). For growth curves, cells were seeded in low density in six-well plates and treated with rapamycin $(100 \mathrm{ng} / \mathrm{ml})$ in the next day. Cell proliferation was assessed by cell counting in the following 7 days.

\section{Western-blot}

Total protein extracts were obtained from monolayer cultures of infected PHKs using lysis buffer $(50 \mathrm{mM}$ Tris- $\mathrm{HCl}, 150 \mathrm{mM} \mathrm{NaCl}, 1 \% \mathrm{NP}-40,0.5 \%$ Sodium deoxycholate, $0.1 \%$ SDS) supplemented with complete mini proteases inhibitors cocktail (Roche Diagnostics $\mathrm{GmbH}$, Mannheim, Germany). Whole cell lysates $(60 \mu \mathrm{g})$ were subjected to SDS-PAGE and transferred to PVDF membranes (GE Healthcare, Buckinghamshire, UK). Membranes were blocked with $5 \%$ non-fat dry milk and incubated with PLD antibody (1:300; Upstate Biotechnology, Lake Placid, NY, USA), pRB antibody (1:500; Novocastra NCL-RB-358; Leica Biosystems, Newcastleupon-Tyne, UK), actin antibody (1:1000; Sigma-Aldrich, St. Louis, MO, USA), anti-HPV-16 E6 antibody (1:500) and anti-HPV-16 E7 antibody (1:500) from Arbor Vita Corporation (Fremont, CA, USA). The immunoreactive bands were visualized by chemiluminescence using ECL reagents (GE Healthcare, Buckinghamshire, UK).

\section{Measurement of phospholipase $\mathrm{D}$ activity}

To measure PLD activity, PHK infected with different recombinant retrovirus were plated in $100 \mathrm{~mm}$ culture dishes and allowed to reach about $80 \%$ confluence. Cells were then pre-labeled with $\left[{ }^{3} \mathrm{H}\right]$ myristic acid (Perkin-Elmer, Waltham, MA, USA) $(6 \mu \mathrm{Ci}, 30 \mathrm{Ci} /$ $\mathrm{mmol}$ ) in $4 \mathrm{ml}$ of culture medium for $5 \mathrm{~h}$. PLD activity was determined by measuring the formation of $\left[{ }^{3} \mathrm{H}\right]$ phosphatidylbutanol (PtBt), the product of PLDmediated trans-phosphatidylation, in the presence of 0.8\% 1-Butanol (Sigma-Aldrich, St. Louis, MO, USA). Lipid extraction and characterization were performed by thin layer chromatography (TLC). Briefly, lipid extracts were counted in a scintillation counter to normalize all samples. Approximately 500.000 CPM of each sample were spotted onto TLC plates (silica gel 60A, Fisher Scientific, Fair Lawn, NJ, USA). TLC were developed with the upper organic phase of a mixture containing ethyl acetate:iso-octane:glacial acetic acid:
$\mathrm{H} 2 \mathrm{O}$ (1.1:0.5:0.2:1, vol/vol) and allowed to dry before being sprayed with En3hancer Spray (Perkin Elmer, IL, USA). Phosphatidilbutanol was detected by autoradiography with Kodak BioMax MR Film (Kodak, Rochester, NY, USA).

PLD activity in control and HPV gene-expressing primary human keratinocytes after $\mathrm{pRb}$ downregulation was determined using the Phospholipase D Assay Kit (\#700590, Cayman Chemicals, Ann Arbor, MI, USA) according to the manufacturer's instructions.

\section{Statistical analysis}

Statistical analyses were performed by student's unpaired t-test using Graphpad Prism Software (Graphpad Software, La Jolla, CA). All the experiments were performed at least three times. $p$-values were considered two-tailed and significance was defined as $p<0.05$."

\section{Results}

HPV-16 E7 expression increases PLD protein expression and activity

PLD1 and PLD2 catalyze the hydrolysis of phosphatidylcholine (PC) to phosphatidic acid (PA) and choline [23]. Due to their vital role in cell signaling and proliferation we sought to investigate if HPV-16 E7 expression could promote any alteration in PLD expression and activity. Our results show that primary human keratinocytes (PHK), expressing HPV-16 E6 and E7 or E7 alone, show an increase in both PLD1 and PLD2 isoforms when compared with keratinocytes transduced only with the empty vector (Fig. 1a). This fact was paralleled by an increase in PLD activity (Fig. 1b). E6 expression alone did not promote any alterations in PLD activation (Additional file 1: Figure S1). Interestingly, we observed that E7 ability to induce PLD expression and activation is dependent on the integrity of its $\mathrm{LxCxE}$ motif, as the $\mathrm{E}^{\mathrm{E} 26 \mathrm{G}}$ mutant failed to induce PLD expression or increase its activity (Fig. 1a and b). An intact LxCxE motif enables E7 protein to bind $\mathrm{pRb}$ protein leading to the release of E2F transcriptional factor and progression into $S$ phase $[24,25]$. On the other hand, the $\mathrm{E} 7$ mutant (E7 $\left.{ }^{\mathrm{CVQ} 68-70 \mathrm{AAA}}\right)$, that keeps the ability to destabilize pRb family members [26], was able to upregulate PLD like the WT E7 protein. Altogether these data indicates that HPV-16 E7 promotes an upregulation in PLD expression and activity and this effect is dependent on the integrity of its LxCxE motif.

\section{HPV-16 E7 induces PLD activation in a pRb dependent- manner}

We investigated if $\mathrm{pRb}$ inactivation, induced by HPV-16 E7, could be linked to PLD increased activation. To address this question, foreskin primary human keratinocytes (PHK) were transduced with two different shRNAs 


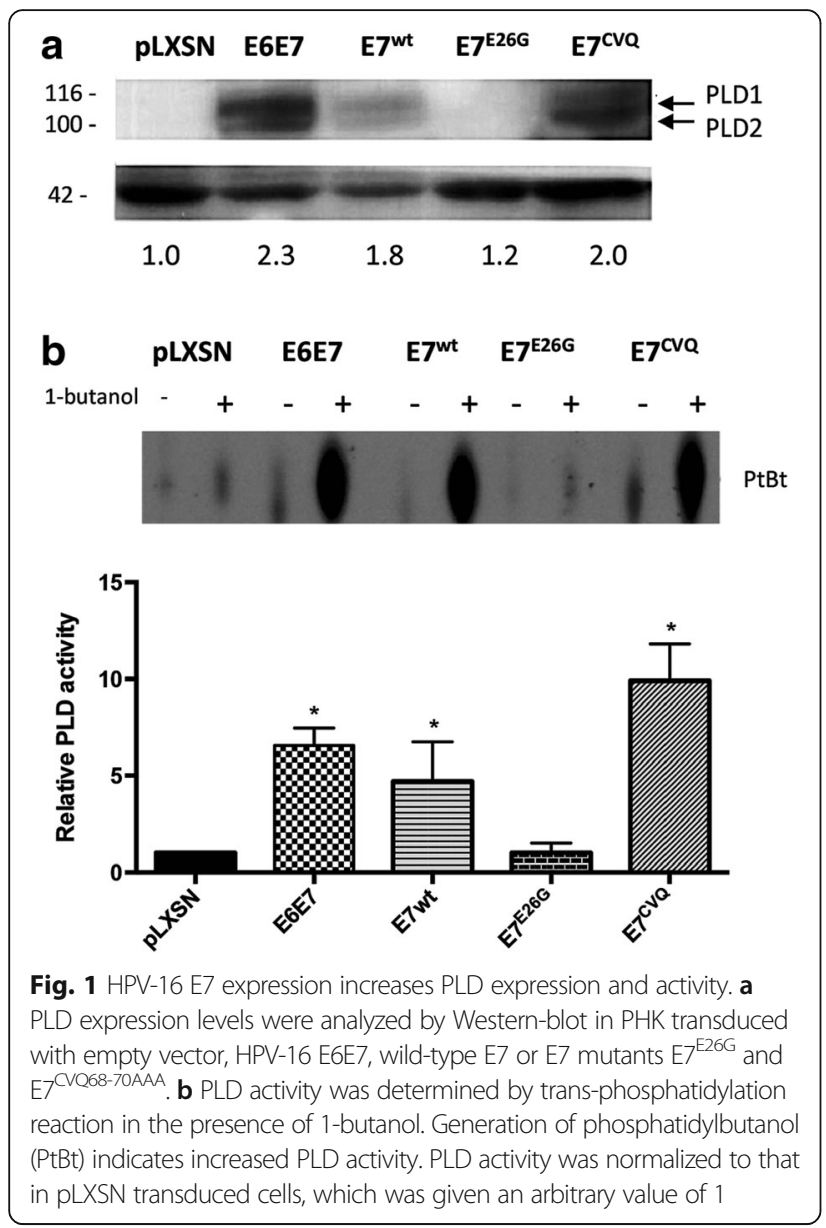

targeting $\mathrm{pRb}$. Retinoblastoma protein was strongly downregulated in both cell lines when compared to PHK transducing scrambled shRNA (Fig. 2a). Moreover, PLD activity was strongly upregulated in cells with pRb depleted (Fig. 2b). This result indicates that PLD activation, induced by E7, is linked to its ability to induce $\mathrm{pRb}$ degradation.

\section{HPV-16 E7 expression confers resistance to the antiproliferative effect of rapamycin}

Elevated PLD activity has been previously linked to rapamycin resistance [18]. Rapamycin is a highly specific inhibitor of mTOR and has been widely used to block cell proliferation [27]. Considering this, we sought to study the effect of rapamycin in the proliferation of human keratinocytes expressing HPV-16 main oncogenes in organotypic raft cultures of human keratinocytes. These cultures exhibit highly reduced p53 and pRb expression levels as an indication of the presence of functional E6 and E7 (Additional file 2: Figure S2a). HPV-16 E6 and E7 expression was also confirmed by Western-blot (Additional file 2: Figure S2b). In keratinocytes transduced with empty
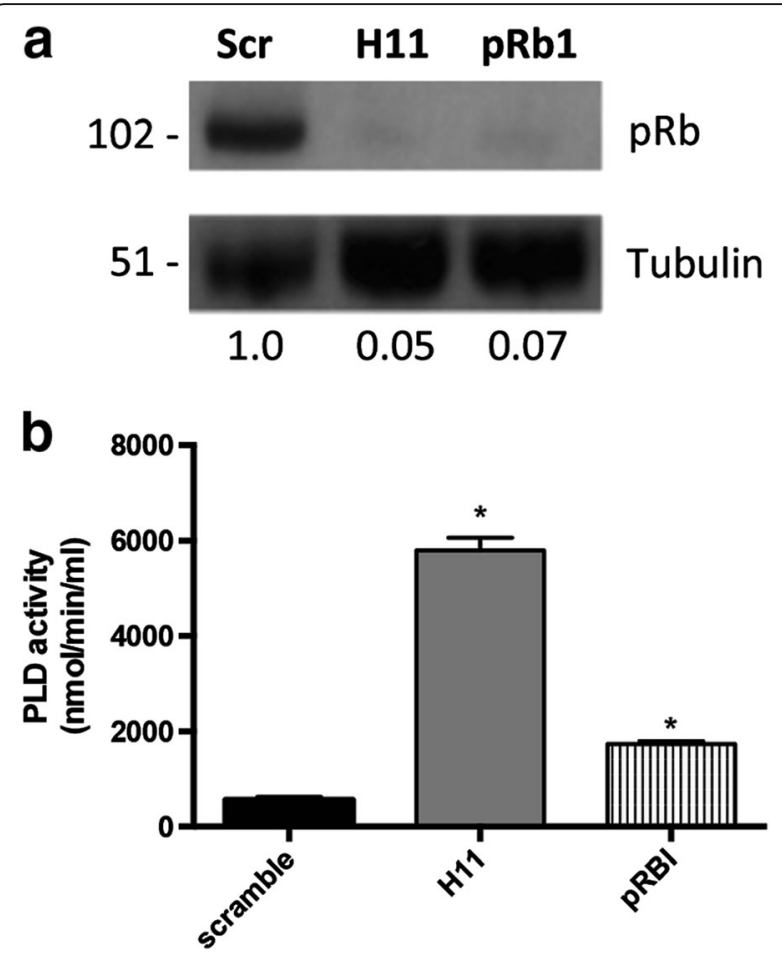

Fig. 2 pRb downregulation leads to PLD activation in PHK. a Expression of $\mathrm{pRb}$ in PHK was silenced using lentiviral particles codifying specific shRNAs. Silencing efficiency was determined by western blot in 30 micrograms of total protein extracts. $\mathbf{b}$ The effect of pRb silencing on PLD activity was determined using Phospholipase D kit according to manufacture instructions. Error bars represent the standard deviation for three independent experiments. $\left(^{*}\right) p<0.05$

vector, from now on referred as control cultures, DNA synthesis was observed only in cells from the basal and parabasal layers of the epithelium (Fig. 3a). After being treated with rapamycin, control cultures showed 50\% less BrdU incorporation than the untreated tissue (Fig. 3b). On the other hand, organotypic cultures of keratinocytes expressing E6E7 were significantly resistant to the antiproliferative effect of rapamycin (Fig. 3a and b). In organotypic cultures expressing only HPV-16 E6, BrdU incorporation rate decreased by $40 \%$ after rapamycin treatment (Fig. 3a and b). Surprisingly, when PHK were transduced only with HPV-16 E7 alone, rapamycin treatment promoted an increase in BrdU incorporation. Growth curve of monolayer cultures of keratinocytes treated with $100 \mathrm{ng} / \mathrm{ml}$ rapamycin for 7 days also indicate that PHK transduced with HPV-16 E7 alone proliferate much faster than PHK transduced with the empty vector (Fig. 3c). Interestingly, we also found that rapamycin treatment increased rather than decreased PLD activity in PHK expressing HPV-16 E7 (Fig. 3d). Our results show that HPV-16 E7 expression in primary human keratinocytes not only confers resistance to the antiproliferative 

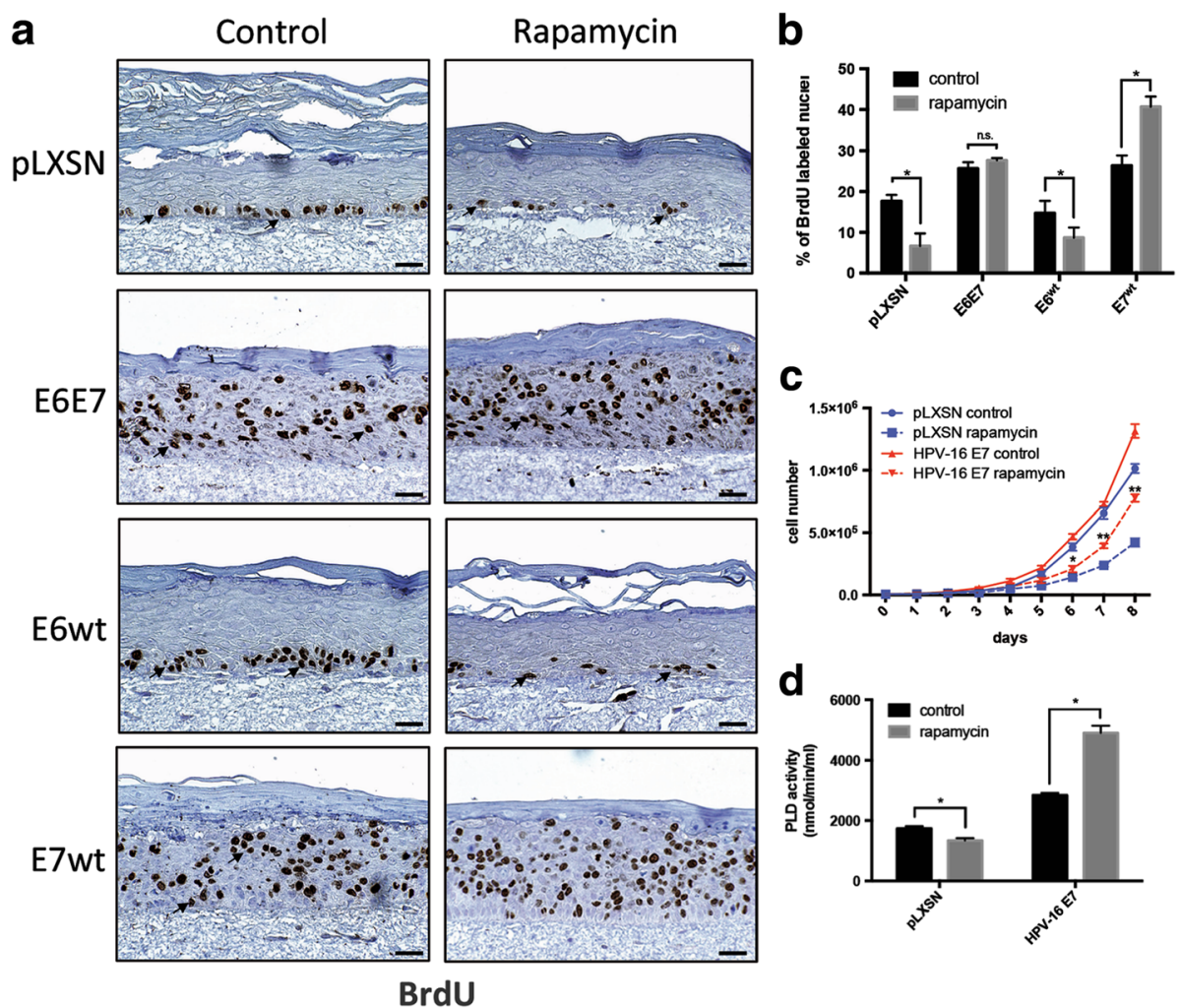

BrdU

Fig. 3 HPV-16 E7 expression confers resistance to the antiproliferative effect of rapamycin. a DNA synthesis in organotypic cultures of keratinocytes was detected by BrdU incorporation followed by immunohistochemistry. Arrows indicate BrdU-positive nuclei. b The percentage of BrdU-positive/total nuclei was determined by direct nuclei counting. The bars correspond to values obtained in at least three independent different experiments. ${ }^{*}$ ) $p<0.05$. c Growth curve of monolayer cultures of keratinocytes treated with $100 \mathrm{ng} / \mathrm{ml}$ rapamycin for 7 days. Results are representative of three independent experiments performed in triplicates. $\left(^{*}\right) p<0.05 ;\left(^{* *}\right) p<0.001$. d Rapamycin treatment is associated with increased PLD activity in cultures of PHK expressing HPV16 E7. PLD activity was determined as described in Fig. 2b. Scale bars, $20 \mu \mathrm{m}$

effect of rapamycin, but also promotes proliferation in organotypic cultures expressing only this oncoprotein.

We also investigated if the integrity of the $\mathrm{LxCxE} \mathrm{E} 7$ motif could affect rapamycin resistance. Our results show that $\mathrm{E} 7^{\mathrm{E} 26 \mathrm{G}}$ expressing cultures were as sensitive to rapamycin as control samples (Fig. 4a and b). On the other hand, DNA synthesis was not affected by rapamycin in cultures expressing the E7CVQ68-70AAA mutant (Fig. 4a and b). We also observed that PHK expressing shRNA against $\mathrm{pRb}$ are much more resistant to rapamycin treatment than those transduced with scrambled shRNA (Fig. 4c and d). This result indicates that rapamycin resistance observed in these cultures is associated to the ability of E7 to induce pRb degradation.

\section{Discussion}

A growing body of evidences gathered during the past few years point toward the role of PA in mTOR activation [15]. More recently, PA was identified as a major product capable of displacing DEPTOR, a mTOR binding protein that normally functions to inhibit both mTORC1 and mTORC2 pathways [17]. The major cellular mechanism for generating PA is through the hydrolysis of phosphatidylcholine by PLD [20]. Here we show that HPV-16 E7, one of the major HPV-16 oncoproteins, is able to induce both PLD expression and activity. Interestingly, PLD has been considered a critical regulator of cell proliferation and abnormalities in its activity have been observed in many human cancers [23]. Additionally, PLD activity is elevated in cells transformed by a variety of oncogenes including $v-S r c, v-R a s, v-$ Fps and v-Raf [23]. We also demonstrate that PLD activation induced by E7 is dependent on the integrity of the LxCxE motif. This particular region of HPV-16 E7 is known to promote AKT activation in primary human keratinocytes grown in organotypic cultures [28]. The $\mathrm{LxCxE}$ motif of high-risk HPVs is also responsible for binding $\mathrm{pRb}$ leading to E2F release. For this reason it was previously linked to the ability of HPV-16 E7 to induce cellular transformation $[25,26]$. Considering this, we sought to investigate if $\mathrm{pRb}$ inactivation could promote PLD activation. Our results show that PHK depleted of $\mathrm{pRb}$ present an increase in PLD expression and activity. Interestingly, E2F putative 


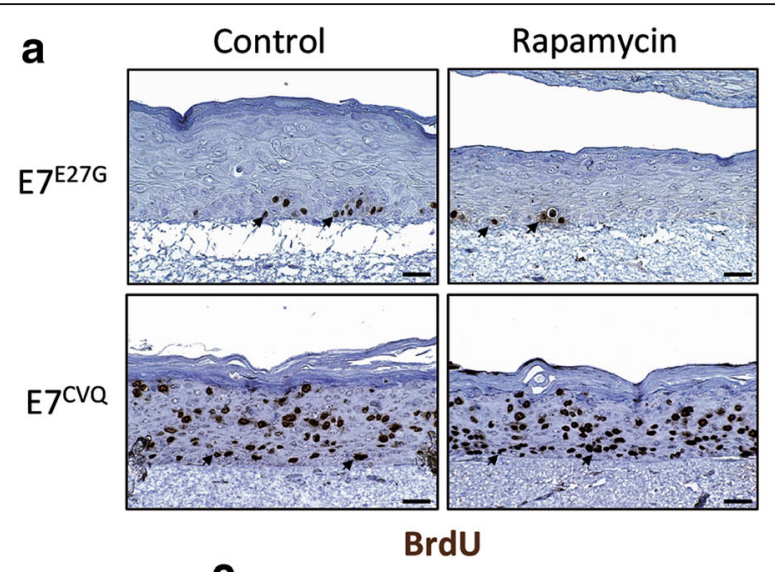

C

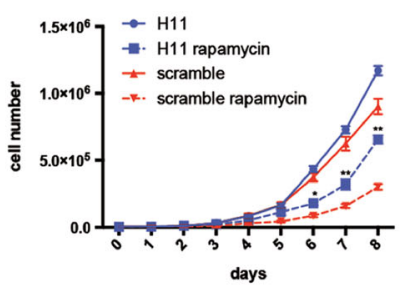

b

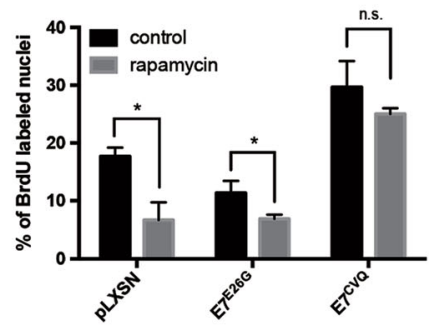

d

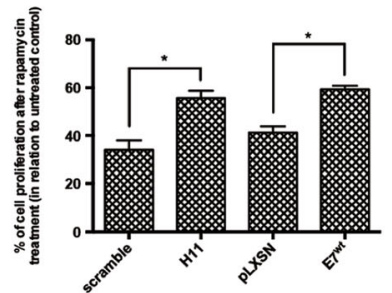

Fig. 4 E7-mediated rapamycin resistance requires an intact LXCXE motif. a DNA synthesis in organotypic culture of keratinocytes expressing HPV-16 E7 mutants was detected by BrdU staining. Arrows indicate positive nuclei. b The percentage of BrdU-positive/total nuclei was determined by direct nuclei counting. The bars correspond to values obtained in at least three independent experiments. $\left(^{*}\right) p<0.05$. c Growth curve of monolayer cultures of keratinocytes treated with $100 \mathrm{ng} / \mathrm{ml}$ rapamycin for 7 days. Results are representative of three independent experiments performed in triplicates. $\left(^{*}\right) p<0.05 ;\left(^{* *}\right) p<0.001$. d Alamar Blue cell proliferation assay was used to evaluate the effect of rapamycin on the proliferation of PHK silenced for pRb expression HPV16 E7 transduced PHKs. Gene silencing was performed as described in Fig. 2. Experiments were carried out in triplicate for each time point. Scale bars, $20 \mu \mathrm{m}$

binding sites were identified in PLD1 and PLD2 promoters using the TRANSFAC database [29] and resistance to mTOR inhibitors could be found in cells with defective regulation of the retinoblastoma protein checkpoint [30]. In line with this observation and the fact that PLD overexpression also confers resistance to the mTOR inhibitor rapamycin, we investigated if cells expressing HPV-16 E7 could also display rapamycin resistance. Our results indicate that HPV-16 E7 is also capable to confer resistance to the antiproliferative effect of rapamycin. Supporting our previous observation, this resistance was also associated to the integrity of the LxCxE motif. This result is not without precedent once E7 is also capable of inducing resistance to other cytostatic agents such as TGF- $\beta$ and TNF in an LxCxE motif dependent-manner [31-33].

One limitation of our study is related to the fact that exogenous PLD expression is associated to human keratinocyte differentiation [21] which precludes the possibility to test directly the effect of PLD overexpression in rapamycin resistance in normal PHK. Nonetheless, our results highlight the importance of HPV-16 E7 in bypassing negative growth regulatory signals [34].

Intriguingly, we found that cultures of keratinocytes expressing only HPV-16 E7 presented an increase in proliferation and an increase in PLD activity after rapamycin treatment. Although this effect was not seen in cells expressing HPV-16 E6 concomitantly, this observation could help us to understand why HPV-associated tumor xenografts generated in immuno-compromised mice grow slower when rapamycin is administered daily to the animals, but fail to lead to any long-term cure

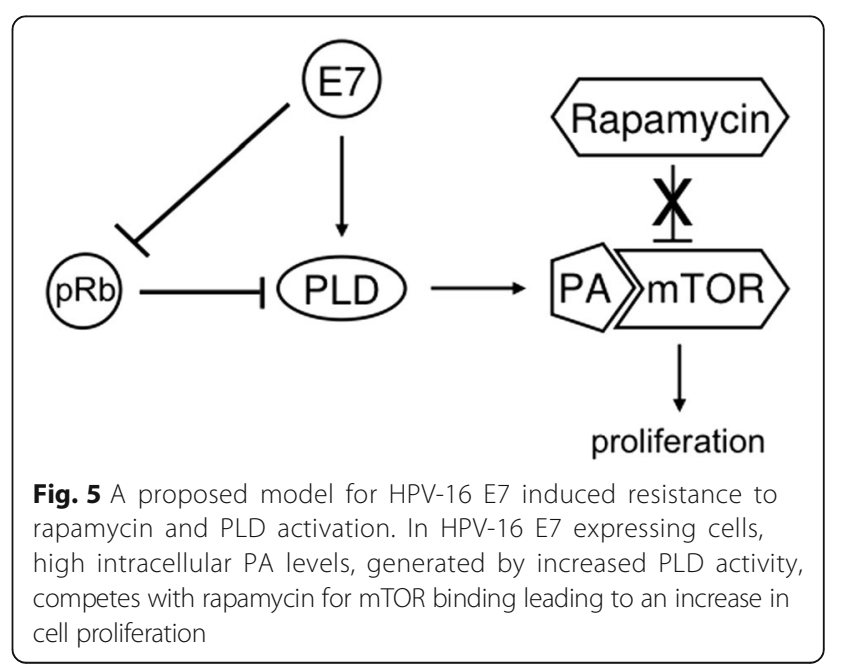


[35]. Even with the treatment prolonging survival and delaying cell proliferation, tumors cells could still grow ultimately affecting survival [35]. For this reason, several studies are suggesting the use of rapamycin in combination with other therapeutic drugs [36]. In fact, rapamycin and rapamycin derivatives are being proposed as a concurrent agent to standard-of-care cisplatin/radiation therapy to attenuate tumor lactate production and induce regression of (HPV)-related head and neck squamous cell carcinomas (HNSCC) [36]. A proposed model describing our findings is presented in Fig. 5.

\section{Conclusions}

Our work present evidences that HPV-16 E7 up-regulates PLD activity. It also shows that the increase in PLD activation is related to the ability of E7 to induce pRb degradation. Moreover, we show that cells depleted of $\mathrm{pRb}$ expression exhibit higher PLD activity. Supporting our findings we present data indicating that both HPV-16 E7 expression and $\mathrm{pRb}$ depletion lead to resistance to the antiproliferative effect of rapamycin. Considering the fact that rapamycin and rapamycin analogs are being combined with other chemotherapeutic drugs, it is possible that rapamycin may be associated with PLD inhibitors to circumvent rapamycin resistance exhibited by many types of human cancers, including those related to HPV. Further studies are warranted.

\section{Additional files}

Additional file 1: Figure S1. HPV-16 E6 did not affect PLD activity. (PDF $127 \mathrm{~kb}$ )

Additional file 2: Figure S2. HPV-16 E6 and E7 expression affect p53 and $\mathrm{pRb}$ expression. (PDF $116 \mathrm{~kb}$ )

\section{Abbreviations}

BPE: Bovine pituitary extract; Brdu: Bromodeoxyuridine; DAB: Diaminobenzidine; HNSCC: Head and neck squamous cell carcinomas; HPV: Human Papillomavirus; MOI: Multiplicity of infection; mTOR: Mammalian target of rapamycin; mTORC1: MTOR complex 1; PA: Phosphatidic acid; PC: Phosphatidylcholine; PHK: Primary human keratinocytes; PI3K: Phosphatidylinositol (PI)-3-kinase; PLD: Phospholipase D; pRb: Retinoblastoma protein; PtBt: Phosphatidylbutanol

\section{Acknowledgments}

We thank Dr. David Foster (Hunter College of the City University of New York) for sharing the protocol for PLD activity detection and Carlos Ferreira do Nascimento and Severino Ferreira from the ACCamargo Cancer Center for technical assistance with histological samples. We also thank Vanesca de Souza Lino for technical assistance with Western-blots.

\section{Funding}

This work was supported by grants from: Ludwig Institute for Cancer Research; Fundação de Amparo a pesquisa do Estado de São Paulo (FAPESP) to Tatiana Rabachini (2003/14008-9), Enrique Boccardo (2010/20002-0), Katia Regina Perez (05/59142-2), lolanda Midea Cuccovia, Luisa Lina Villa (2008/ 03232-1 and 2008/57889-1); Coordenação de Aperfeiçoamento de Pessoal de Nivel Superior (CAPES) to Rubiana Andrade and Conselho Nacional de Pesquisa e Desenvolvimento (CNPq) to Rubiana Andrade and Luisa Lina Villa (573799/2008-3), Enrique Boccardo (480552-2011) and Iolanda Midea
Cuccovia. The funders had no role in study design, data collection and interpretation, or the decision to submit the work for publication.

\section{Availability of data and materials}

The datasets used and/or analysed during the current study are available from the corresponding author on reasonable request.

\section{Authors' contributions}

TRA, EB, IMC, and LLV designed the research, supervised all experiments, performed the statistical analysis and drafted this paper. TRA, KRP and RA executed PLD assays, WB and proliferation assays. TRA, EB and SN performed PHK infections, organotypic cultures of keratinocytes and immunohistochemistry. TRA, EB and LLV discussed the results and revised the manuscript. All authors read and approved the final manuscript.

Ethics approval and consent to participate Not applicable.

\section{Competing interests}

The authors declare that they have no competing interests.

\section{Publisher's Note}

Springer Nature remains neutral with regard to jurisdictional claims in published maps and institutional affiliations.

\section{Author details}

'Ludwig Institute for Cancer Research - Hospital Sírio-Libanês, São Paulo, SP, Brazil. ²Departamento de Bioquímica, Instituto de Química, Universidade de São Paulo, São Paulo, SP, Brazil. 'Departamento de Microbiologia, Instituto de Ciências Biomédicas, Universidade de São Paulo, São Paulo, SP, Brazil. ${ }^{4}$ Departamento de Biofísica, Escola Paulista de Medicina, Universidade Federal de São Paulo, São Paulo, SP, Brazil. ${ }^{5}$ Centro de Patologia do Instituto Adolfo Lutz, São Paulo, SP, Brazil. 'Faculdade de Medicina da Universidade de São Paulo, Instituto do Câncer do Estado de São Paulo, São Paulo, SP, Brazil.

Received: 28 September 2017 Accepted: 17 April 2018

Published online: 27 April 2018

\section{References}

1. Pisani P, Bray F, Parkin DM. Estimates of the world-wide prevalence of cancer for 25 sites in the adult population. Int J Cancer. 2002;97(1):72-81.

2. Walboomers JM, Jacobs MV, Manos MM, Bosch FX, Kummer JA, et al. Human papillomavirus is a necessary cause of invasive cervical cancer worldwide. J Pathol. 1999:189(1):12-9.

3. D'Souza G, Kreimer AR, Viscidi R, Pawlita M, Fakhry C, et al. Case-control study of human papillomavirus and oropharyngeal cancer. N Engl J Med. 2007;356(19):1944-56.

4. Gillison ML, D'Souza G, Westra W, Sugar E, Xiao W, et al. Distinct risk factor profiles for human papillomavirus type 16-positive and human papillomavirus type 16-negative head and neck cancers. J Natl Cancer Inst. 2008;100(6):407-20

5. Paavonen J. Human papillomavirus infection and the development of cervical cancer and related genital neoplasias. Int J Infect Dis. 2007; 11 (Suppl 2):S3-9.

6. Clifford GM, Smith JS, Plummer M, Munoz N, Franceschi S. Human papillomavirus types in invasive cervical cancer worldwide: a meta-analysis. $\mathrm{Br} J$ Cancer. 2003:88(1):63-73.

7. Hawley-Nelson P, Vousden KH, Hubbert NL, Lowy DR, Schiller JT. HPV16 E6 and E7 proteins cooperate to immortalize human foreskin keratinocytes. EMBO J. 1989;8(12):3905-10.

8. Blanton RA, Perez-Reyes N, Merrick DT, McDougall JK. Epithelial cells immortalized by human papillomaviruses have premalignant characteristics in organotypic culture. Am J Pathol. 1991;138(3):673-85.

9. Scheffner M, Werness BA, Huibregtse JM, Levine AJ, Howley PM. The E6 oncoprotein encoded by human papillomavirus types 16 and 18 promotes the degradation of p53. Cell. 1990;63(6):1129-36.

10. Boyer SN, Wazer DE, Band V. E7 protein of human papilloma virus-16 induces degradation of retinoblastoma protein through the ubiquitinproteasome pathway. Cancer Res. 1996;56(20):4620-4. 
11. Hebner CM, Laimins LA. Human papillomaviruses: basic mechanisms of pathogenesis and oncogenicity. Rev Med Virol. 2006;16(2):83-97.

12. Buchkovich NJ, Yu Y, Zampieri CA, Alwine JC. The TORrid affairs of viruses: effects of mammalian DNA viruses on the PI3K-Akt-mTOR signalling pathway. Nat Rev Microbiol. 2008;6(4):266-75.

13. Zhang L, Wu J, Ling MT, Zhao L, Zhao KN. The role of the PI3K/Akt/mTOR signalling pathway in human cancers induced by infection with human papillomaviruses. Mol Cancer. 2015;14:87.

14. Fang Y, Vilella-Bach M, Bachmann R, Flanigan A, Chen J. Phosphatidic acidmediated mitogenic activation of mTOR signaling. Sci. 2001;294(5548):1942-5.

15. Sun Y, Chen J. mTOR signaling: PLD takes center stage. Cell Cycle. 2008; 7(20):3118-23.

16. Yoon MS, Du G, Backer JM, Frohman MA, Chen J. Class III PI-3-kinase activates phospholipase $D$ in an amino acid-sensing mTORC1 pathway. J Cell Biol. 2011:195(3):435-47.

17. Yoon MS, Rosenberger CL, Wu C, Truong N, Sweedler JV, Chen J. Rapid mitogenic regulation of the mTORC1 inhibitor, DEPTOR, by phosphatidic acid. Mol Cell. 2015;58(3):549-56.

18. Chen Y, Zheng Y, Foster DA. Phospholipase D confers rapamycin resistance in human breast cancer cells. Oncogene. 2003;22(25):3937-42.

19. Toschi A, Lee E, Xu L, Garcia A, Gadir N, Foster DA. Regulation of mTORC1 and mTORC2 complex assembly by phosphatidic acid: competition with rapamycin. Mol Cell Biol. 2009:29(6):1411-20.

20. Foster DA. Regulation of mTOR by phosphatidic acid? Cancer Res. 2007; 67(1):1-4.

21. Jung EM, Betancourt-Calle S, Mann-Blakeney R, Griner RD, Bollinger Bollag W. Sustained phospholipase D activation is associated with keratinocyte differentiation. Carcinogenesis. 1999;20(4):569-76.

22. McLaughlin-Drubin ME, Münger K. The human papillomavirus E7 Oncoprotein. Virology. 2009;384(2):335-44.

23. Foster DA, Xu L. Phospholipase $D$ in cell proliferation and cancer. Mol Cancer Res. 2003;1 (11):789-800.

24. Helt AM, Galloway DA. Mechanisms by which DNA tumor virus oncoproteins target the Rb family of pocket proteins. Carcinogenesis. 2003;24(2):159-69. https://doi.org/10.1093/carcin/24.2.159.

25. Demers GW, Espling E, Harry JB, Etscheid BG, Galloway DA. Abrogation of growth arrest signals by human papillomavirus type $16 \mathrm{E} 7$ is mediated by sequences required for transformation. J Virol. 1996;70(10):6862-9.

26. Helt AM, Galloway DA. Destabilization of the retinoblastoma tumor suppressor by human papillomavirus type $16 \mathrm{E} 7$ is not sufficient to overcome cell cycle arrest in human keratinocytes. J Virol. 2001;75(15):6737-47.

27. Hidalgo $M$, Rowinsky EK. The rapamycin-sensitive signal transduction. pathway as a target for cancer therapy. Oncogene. 2000;19(56):6680-6.

28. Menges CW, Baglia LA, Lapoint R, McCance DJ. Human papillomavirus type 16 E7 up-regulates AKT activity through the retinoblastoma protein. Cancer Res. 2006;66(11):5555-9.

29. Wingender E, Chen X, Hehl R, Karas H, Liebich I, Matys V, Meinhardt T, Prüss M, Reuter I, Schacherer F. TRANSFAC: an integrated system for gene expression regulation. Nucleic Acids Res. 2000;28:316-9.

30. Kurmasheva RT, Huang S, Houghton PJ. Predicted mechanisms of resistance to mTOR inhibitors. Br J Cancer. 2006;95(8):955-60.

31. Basile JR, Zacny V, Munger K. The cytokines tumor necrosis factor-alpha (TNF-alpha ) and TNF-related apoptosis-inducing ligand differentially modulate proliferation and apoptotic pathways in human keratinocytes expressing the human papillomavirus-16 E7 oncoprotein. J Biol Chem. 2001; 276(25):22522-8

32. Boccardo E, Noya F, Broker TR, Chow LT, Villa LL. HPV-18 confers resistance to TNF-alpha in organotypic cultures of human keratinocytes. Virology. 2004;328(2):233-43.

33. Boccardo E, Manzini Baldi CV, Carvalho AF, Rabachini T, Torres C, et al. Expression of human papillomavirus type 16 E7 oncoprotein alters keratinocytes expression profile in response to tumor necrosis factor-alpha. Carcinogenesis. 2010;31(3):521-31.

34. Stelzer MK, Pitot HC, Liem A, Lee D, Kennedy GD, Lambert PF. Rapamycin inhibits anal carcinogenesis in two preclinical animal models. Cancer Prev Res (Phila). 2010;3(12):1542-51.

35. Li J, Kim SG, Blenis J. Rapamycin: one drug, many effects. Cell Metab. 2014; 19(3):373-9.

36. Coppock JD, Vermeer PD, Vermeer DW, Lee KM, Miskimins WK, et al. mTOR inhibition as an adjuvant therapy in a metastatic model of HPV+ HNSCC. Oncotarget. 2016;7(17):24228-41.

\section{Ready to submit your research? Choose BMC and benefit from:}

- fast, convenient online submission

- thorough peer review by experienced researchers in your field

- rapid publication on acceptance

- support for research data, including large and complex data types

- gold Open Access which fosters wider collaboration and increased citations

- maximum visibility for your research: over $100 \mathrm{M}$ website views per year

At BMC, research is always in progress.

Learn more biomedcentral.com/submissions 